\title{
Associations of Household Food Security with Health-Related Quality of Life in Various Districts of Tehran
}

\author{
Mahboobeh Darman ${ }^{1}$, Ali Gholami ${ }^{2,3}$, Hamid Reza Baradaran ${ }^{4,5,6}$, Negin Agha-Mohseni ${ }^{7}$, Mohsen Asadi-Lari ${ }^{8^{*}}$ \\ 1-Master of Epidemiology, Non-communicable Disease Expert, Center for Noncommunicable Disease Control \& Prevention, Deputy of Health, Ministry \\ of Health and Medical Education, Tehran, Iran \\ 2-Noncommunicable Diseases Research Center, Neyshabur University of Medical Sciences, Neyshabur, Iran, \\ 3-Department of Epidemiology \& Biostatistics, School of Public Health, Neyshabur University of Medical Sciences, Neyshabur, Iran \\ 4-Department of Epidemiology, School of Public Health, Iran University of Medical Sciences, Tehran, Iran \\ 5-Ageing Clinical and Experimental Research Team, Institute of Applied Health Sciences, School of Medicine, Medical Sciences and Nutrition \\ University of Aberdeen, Aberdeen, UK \\ 6-Endocrine Research Center, Institute of Endocrinology and Metabolism, Iran University of Medical Sciences, Tehran, Iran \\ 7- Midwifery Student, Department of Midwifery, Azad University of Medical Science, Tehran, Iran \\ 8- Professor of Epidemiology; Department of Epidemiology, School of Public Health; Oncopathology Research Center; Iran University of Medical \\ Science, Tehran, Iran
}

\section{A B S T R A C T}

Background and Objectives: Food insecurity is recognized as a serious public health problem worldwide. Since household food security may affect health-related quality of life, the present study was carried out to assess associations of household food security with health-related quality of life in various districts of Tehran, Iran.

Materials and Methods: Data of this cross-sectional study were collected from the Urban Health Equity Assessment and Response Tool (Urban HEART-2) Survey in Tehran Capital City, Iran, 2011, using multistage cluster random sampling method. From each household, one person was selected to participate. Data collection instruments included 6item short-form to measure household food security status and SF-12V2 questionnaire to evaluate health-related quality of life. From 33252 people, 30521 people with ages of 18 years or greater were included in this study. Multiple linear regression model was used to assess independent effects of household food security on health-related quality of life.

Results: Age range of the participants was 18-90 years with a mean age of 43.85 years \pm 16.2 . Overall, $68.4 \%$ of the participants were female and $35.2 \%$ were male. Moreover, $62.2 \%$ of the participating households belonged to the food secure group. The mean score of the health-related quality of life was $60.5 \pm 19.4$. The mean scores of health-related quality of life varied based on the household food security status in various districts of Tehran $(p<0.001)$. Multiple linear regression model showed significant relationships between health-related quality of life and household food security, adjusting age, gender, education, marital status, family size, body mass index and wealth and deprivation indices $(p<0.001)$.

Conclusions: Results showed associations of the household food security with health-related quality of life in various districts of Tehran. Policy makers are recommended to provide efficient interventions to promote quality of life of urban households based on the social determinants in each district.

Keywords: HRQOL, household food security, food insecurity, Urban HEART-2, Tehran

\section{Introduction}

Health-related quality of life (HRQOL) is a complex concept, often synonymous with health and life satisfaction. Based on the literature reviews, HRQOL includes happiness, satisfaction of expectations and physical and mental capabilities to achieve personal goals and social productivity (1). World health organization
(WHO) has described quality of life (QOL) as "an individual's perception of their position in life in the context of the culture and value systems; in which, they live and in relation to their goals, expectations, standards and concerns". Despite various definitions, still no definitions are available that cover various dimensions of 
this concept; however, scholars agree that HRQOL is a multidimensional, subjective and dynamic concept (2). Quality of urban life is one of the most important areas of urban studies worldwide. This study area is important because of the increasing importance of studies on QOL in monitoring public policy and due to its roles as an effective tool in urban management and planning. Quality of urban life is usually assessed through subjective indicators from the assessment of citizens' perceptions and satisfaction with urban life or use of objective indicators from secondary data (3). Regarding the effects of noncommunicable diseases on human health, household food security (HFS) can be described as a risk factor for a lower HRQOL. Lack of enough incomes, use of poor quality foods, skip of meals and replacement of valuable foods by ready-to-eat cheap foods and snacks can include significant effects on HFS and hence HRQOL.

In 1990, concept of food security was completed as 1) provision of enough foods for all people at all times for active and healthy lives; 2) availability of healthy and adequate foods in terms of quantity and quality; 3) ability and confidence to reach custom foods acceptable to societies. Food security within the current definition is "a sufficient and favorable food consumption pattern that is based on three principles of nourishing, diversity and balance, providing nutritional health. The HFS is defined as "access to enough food by all people at all times for having an active and healthy life, individuals who are food insecure live in hunger or fear of starvation". In general, food insecurity occurs when healthy and adequate foods are restricted and barely available". Food insecurity refers to the lack of access to adequate and healthy food to meet basic needs, which is limited by the quantity, quality and frequency of food absorption and decreases in serum micronutrients (4-6). In the past two decades, food insecurity has been reported as a serious public health problem in world, attracting attention of experts and policy makers. From 1996 to 2015, most countries such as Iran at World Food Summit pledged to decrease hunger by $50 \%$. Therefore, eradication of extreme poverty and hunger as one of the millennium development goals (MDG) was announced by international organizations (7). Food and agriculture organization (FAO) in its latest report (2018) on food insecurity in 150 countries showed that approximately one out of ten people $(9.3 \%)$ in world suffered from severe food insecurity with an estimated 689 million people. In South Africa and West Asia, food security situation is clearly deteriorated (8). Most of these people suffer from long-term energy and nutrient deficiencies and fewer of them suffer from short-term energy and nutrient deficiencies due to natural disasters (7).

Food insecurity is usually a result of multiple causes, including a wide range of phenomena such as famine, food insecurity, poverty, unemployment, economic inflation, illiteracy, nutritional ignorance, accidents, drought and other natural disasters. These factors are partially results of food insecurity. Hunger and disease are the consequences of food insecurity in short-terms; however in long-terms, populations are gradually deprived from core capabilities and cannot contribute to education, economy and production. Decreasing labor productivity due to food insecurity can lead to a 6-10\% reduction in gross domestic product (GDP) (7). Based on the effects of HFS on various physical, mental and social aspects of human health, HFS can improve nutritional issues including overweight, obesity and mental health problems globally. Studies have shown that individuals living in food secure households include a higher HRQOL than those living in food insecure households (9-14). Although several studies have assessed effects of various factors of chronic diseases, aging, educational levels and gender on HRQOL, a few studies have assessed relationships between HFS and HRQOL in Iran. Therefore, the aim of this study was to assess associations between HFS and HRQOL in various districts of Tehran, Iran.

\section{Materials and Methods}

\section{Design and sample}

Data of this cross-sectional study were collected from the urban health equity assessment and response tool (Urban HEART-2) study. The Urban HEART-2 survey was started in various districts of Tehran Capital City, 2011. The Urban HEART-2 study was carried out on random samples selected from Tehran urban population, using multistage cluster random sampling method. First, a map of Tehran was prepared by specifying areas and neighborhoods. Stratified sampling was used in the first and second stages and a total of 22 districts and 368 neighborhoods were selected for the study. In the third step, each block was considered as a cluster. A systematic two-dimensional sampling method was used, using GIS maps to select blocks in each neighborhood. From each household, one person was selected to participate and 33252 people were totally surveyed. Before completing the questionnaires, participants were assured of the confidentiality of information. Questionnaires were completed, using face-to-face method with personal consent of the participants (15-17). In total, 30521 people aged $\geq 18$ years were included in this study.

\section{Measures}

Research tools used in Urban HEART-2 included a 6item short form that focused on measuring HFS statuses as well as a SF-12V2 questionnaire (a generic, multipurpose short-form survey with 12 questions selected from SF-36 health survey. HRQOL data were scored and weighted in two scales of mental and physical functions. 


\section{Household food security questionnaire}

Reliability and validity of the short forms were assessed in Iran by Dastgiri et al. (18). For Questions 1 and 2, 'never' or 'does not know' were reported as negative responses. For Question 4, 'no' or 'only one or two days' were reported as negative responses. For Questions 3, 5 and 6, 'no' or 'does not know' were reported as negative responses. Households that answered negatively to five or six questions were classified in food secure (19).

\section{The SF-12V2 questionnaire}

The SF-12 questionnaire was developed in 1996 by Ware (20). Reliability and validity of this tool were verified in Iran by Montazeri et al. (21). The items were transformed to a 0-100 scale; 100 represented the maximum and 0 represented the minimum HRQOL scores. The SF-12V2 questionnaire included 12 multiple-choice questions and eight dimensions. A specified score assigned to each dimension, showing individual HRQOL in that dimension. These included physical functioning (PF-2 item), role limitations due to the physical problems (RP-2 item), bodily pain (BP-1 item), vitality (VT-1 item), general health (GH-1 item), social functioning (SF-1 item), role limitations due to the emotional problems (RE-2 item) and mental health (MH-2 item). Four dimensions (PF, RP, $\mathrm{BP}$ and $\mathrm{GH}$ ) were associated to the physical aspects of SF$12 \mathrm{~V} 2$ and were led to the scoring of physical component summary (PCS) scales. The other four dimensions (SF, RE, $\mathrm{VT}$ and $\mathrm{MH}$ ) were associated to the mental aspects of SF$12 \mathrm{~V} 2$ and were led to the scoring of mental component summary (MCS) scales. Total HRQOL score was achieved from the mean scores calculated for all dimensions (2224).

\section{Study variables}

Dependent variable included HRQOL and major independent variable included HFS (yes/no). Covariates included gender (female and male), age $(\leq 42$ years and $>$ 42 years), years of education ( $>12$ years and $\leq 12$ years), marital status (married and single/divorced), body mass index $(\mathrm{BMI}<25$ and $\mathrm{BMI} \geq 25)$, family size ( $\leq 3$ people and $>3$ people), wealth index (poorest, poorer, middle, richer and richest), deprivation index [quintile 1 (least deprived), quintile 2 , quintile 3 , quintile 4 and quintile 5 (most deprived)].

\section{Statistical analysis}

In this study, STATA Software v.12 (STATA, USA) was used to analyze collected data. Based on the study objectives, descriptive statistics were carried out, including frequencies, ranges, median, means and standard deviations (SD). To compare the mean scores of HRQOL based on the variables, t-independent and ANOVA tests were used Multiple Linear regression model was used to evaluate the independent effects of HFS with control the effects of other variablesSignificance of the tests was set as $p<0.20$ for univariate and $p<0.05$ for multiple analysis. Wealth index was a composite index, including household asset variables. These variables included 1- home ownership status, 2- number of rooms, 3- residential unit infrastructure, 4- telephone, 5- bathroom, 6- kitchen, 7toilet, 8- car, 9- motorcycle, 10- mobile phone, 11- freezer, 12- dishwasher, 13- microwave and 14- computer. The quintiles were based on weight or score of the collected asset data from each household, using principal component analysis (PCA) method (25-26). Proportions of unemployed people over 16 years old and households with no cars or houses and rates of people at home were used to calculate the deprivation index. Unemployment and overcrowding proportions (+1) were subjected to a $\log$ transformation to normalize raw values. All four variables were then standardized, using Z-score (subtracted the mean values dividing by $\mathrm{SD}$ ). These four standardized scores were summed to achieve a single value, which included the Townsend deprivation index. Knowledge of the mean and SD for each variable was necessary when calculating Townsend scores (27-28).

\section{Ethical considerations}

Informed consent forms were completed by the participants before beginning of the study. Participants filled out the questionnaires anonymously and were assured about confidentiality of their information.

\section{Results}

In general, the current study was carried out on 30521 participants (Figure 1). Age range of the participants was $18-90$ years with a mean age of 43.85 years \pm 16.2 . Overall, $64.8 \%$ of the participants were female and $35.2 \%$ were male. Of the studied households, $54.5 \%$ were consisted of more than three people (1-15 people per family). The BMI reflected overweight and obesity in $54.5 \%$ of the individuals, who lived in Tehran (BMI $\geq 25)$. Demographic characteristics of the participants are represented in Table 1. The mean of HFS in various districts of Tehran (22 districts) was $62.2 \%$. The total mean score of HRQOL was $60.5 \pm 19.4$. Gender, educational level, family size, BMI, wealth index and deprivation index were linked to HRQOL $(p<0.2)$. 


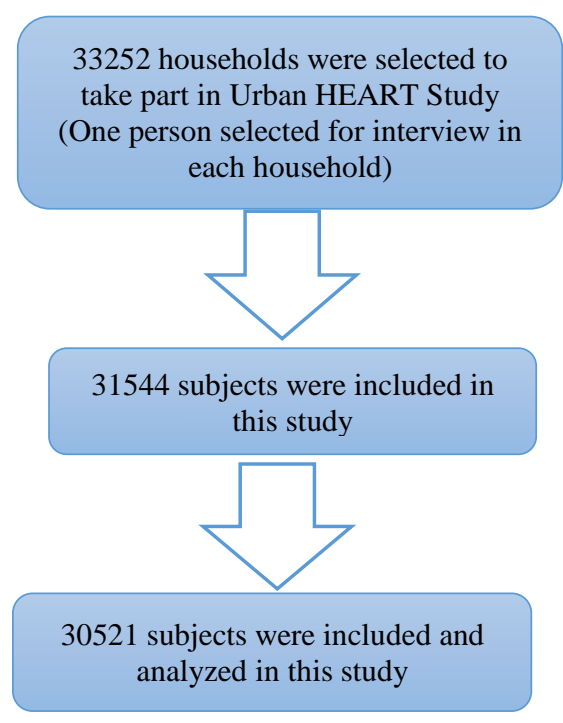

1708 were excluded from the study because individuals Over 18 years of age was selected from each household

Figure 1: Schematic diagram of the study population selection

Table1. Frequency distribution of the participants' demographic characteristics $(n=30521)$

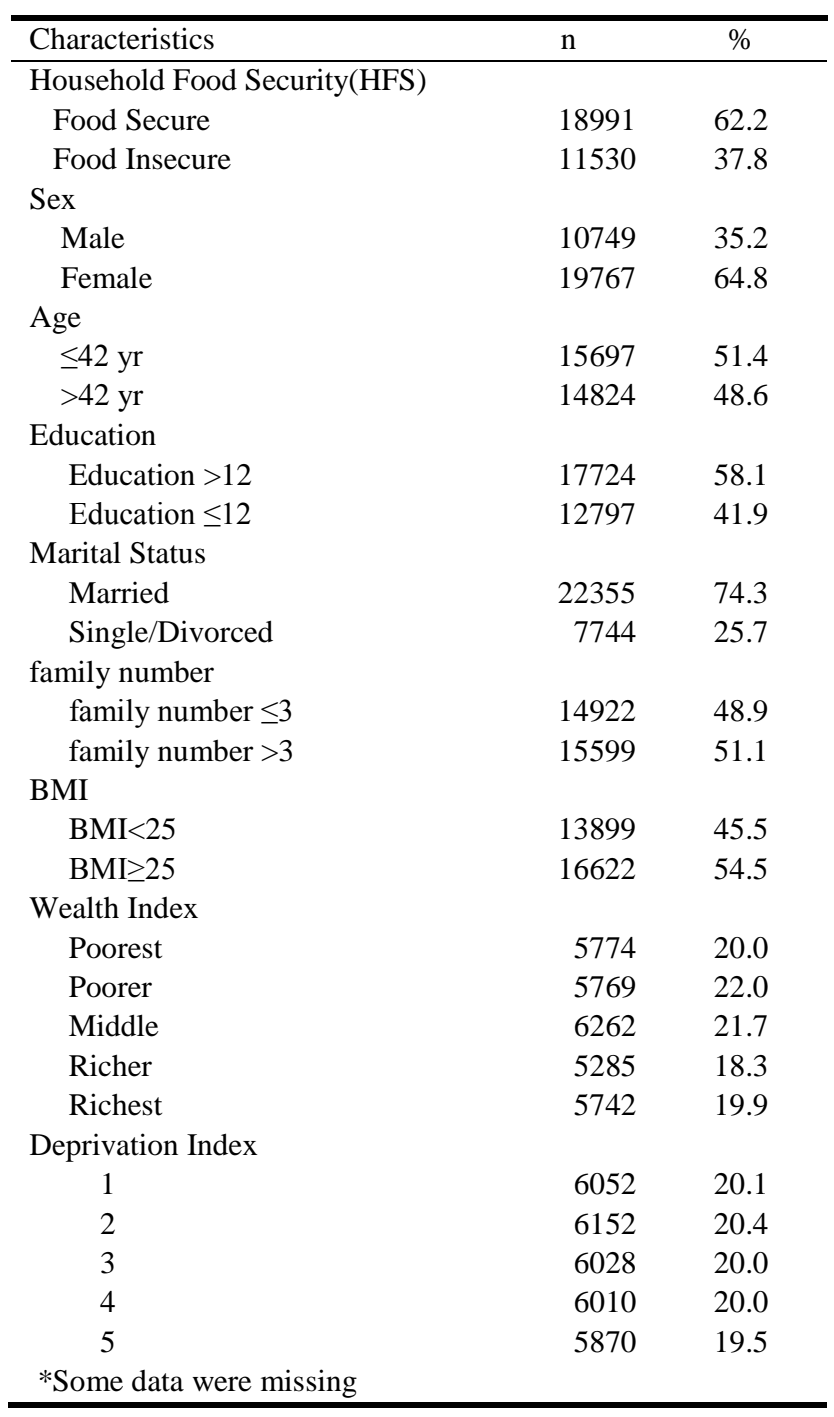

In Table 3, associations between HRQOL and HFS statuses (food secure and food insecure) are shown. As shown in Table 3, the HRQOL mean scores were significantly different based on HFS statuses in various districts of Tehran $(p<0.001)$. The maximum and the minimum mean scores of HRQOL was 66.6 in District 3 and 60.3 in District 12, respectively. The mean of HFS in various districts of Tehran (22 districts) was $62.2 \%$. Significant relationships were seen between the HFS and HRQOL $(p<0.001)$. Effects of HFS on HRQOL varied in various districts of Tehran. Age, gender, educational level, family size, BMI, wealth index and deprivation index were significantly associated to HRQOL $(p<0.001)$. Based on the results of MLR model in Table 4 and Supplementary S1-S12, the HFS included significantly positive relationships with total HRQOL and its eight dimensions by adjusting other variables, including age, gender, educational level, marital status, family size, BMI, wealth index and deprivation index $(p<0.05)$. Based on Table 4, effects of HFS on HRQOL varied in various districts of Tehran; hence, HFS included significant effects on HRQOL in some districts. The highest and the lowest effects of HFS on HRQOL included 8.16 in District 1 and 2.89 in District 22, respectively. 
Table 2. Comparison of the participants' HRQOL mean scores based on the participants' characteristics

\begin{tabular}{|c|c|c|c|}
\hline Variables & $\operatorname{Mean}(\mathrm{SD})$ & $95 \%$ CI for Mean & P-value \\
\hline Total & $60 / 5 \pm 19 / 4$ & $(60 / 3,60 / 8)$ & \\
\hline \multicolumn{4}{|c|}{ Household Food Security(HFS) } \\
\hline Food Secure & $63 / 8 \pm 18 / 8$ & $(63 / 5,64 / 1)$ & \multirow[b]{2}{*}{$<0 / 001$} \\
\hline Food Insecure & $55 / 2 \pm 19 / 3$ & $(54 / 8,55 / 5)$ & \\
\hline \multicolumn{4}{|l|}{ Gender } \\
\hline Male & $62 / 9 \pm 19 / 3$ & $(62 / 5,63 / 2)$ & \multirow[b]{2}{*}{$<0 / 001$} \\
\hline Female & $59 / 3 \pm 19 / 4$ & $(59 / 0,59 / 6)$ & \\
\hline \multicolumn{4}{|l|}{ Age } \\
\hline$\leq 42$ year & $65 / 0 \pm 18 / 5$ & $(64 / 7,65 / 3)$ & \multirow[b]{2}{*}{$<0 / 001$} \\
\hline$>42$ year & $55 / 8 \pm 19 / 2$ & $(55 / 5,56 / 1)$ & \\
\hline \multicolumn{4}{|l|}{ Education } \\
\hline Education $>12$ & $64 / 5 \pm 18 / 6$ & $(64 / 3,64 / 8)$ & \multirow[b]{2}{*}{$<0 / 001$} \\
\hline Education $\leq 12$ & $55 / 0 \pm 19 / 2$ & $(54 / 7,55 / 3)$ & \\
\hline \multicolumn{4}{|l|}{ Marital Status } \\
\hline Married & $60 / 5 \pm 18 / 9$ & $(60 / 2,60 / 7)$ & \multirow[b]{2}{*}{$0 / 280$} \\
\hline Single/Divorced & $60 / 7 \pm 21 / 0$ & $(60 / 3,61 / 2)$ & \\
\hline \multicolumn{4}{|l|}{ Family size } \\
\hline$\leq 3$ & $59 / 3 \pm 19 / 8$ & $(59 / 0,59 / 6)$ & \multirow[b]{2}{*}{$<0 / 001$} \\
\hline$>3$ & $61 / 7 \pm 18 / 9$ & $(61 / 4,62 / 0)$ & \\
\hline \multicolumn{4}{|l|}{ BMI } \\
\hline $\mathrm{BMI}<25$ & $62 / 5 \pm 19 / 4$ & $(62 / 2,62 / 9)$ & \multirow[b]{2}{*}{$<0 / 001$} \\
\hline $\mathrm{BMI} \geq 25$ & $58 / 9 \pm 19 / 3$ & $(58 / 6,59 / 2)$ & \\
\hline \multicolumn{4}{|l|}{ Wealth Index } \\
\hline Poorest & \multicolumn{2}{|c|}{$56 / 0 \pm 20 / 0$} & \multirow{5}{*}{$<0 / 001$} \\
\hline Poorer & \multicolumn{2}{|c|}{$57 / 6 \pm 19 / 6$} & \\
\hline Middle & & $7 \pm 18 / 9$ & \\
\hline Rich & & $8 \pm 19 / 1$ & \\
\hline Richest & & $7 \pm 18 / 0$ & \\
\hline \multicolumn{4}{|l|}{ Deprivation Index } \\
\hline 1 & & $0 \pm 20 / 3$ & \multirow{5}{*}{$<0 / 001$} \\
\hline 2 & & $0 \pm 19 / 7$ & \\
\hline 3 & & $8 \pm 19 / 2$ & \\
\hline 4 & & $4 \pm 18 / 9$ & \\
\hline 5 & & $8 \pm 18 / 6$ & \\
\hline
\end{tabular}

\section{Discussion}

The present study investigated associations of HFS and HRQOL in various districts of Tehran, Iran. The total mean score of HRQOL was $60.5 \pm 19.4$. The maximum and the minimum mean scores of HRQOL included $66.6 \pm 18.4$ in District 3 and $60.3 \pm 17.6$ in District 12, respectively. The mean of HFS in various districts of Tehran (22 districts) was $62.2 \%$. Significant relationships were seen between the HFS and HRQOL ( $p<0.001)$. Effects of HFS on HRQOL varied in various districts of Tehran; the highest effect of HFS on HRQOL included 8.16 in District 1 and the lowest effect included 2.89 in District 22. Almost effects of household food security on HRQOL in District 22 was onethird of that in District 1 . It could be concluded that heterogeneity in District 1 led to decreases in QOL scores, considering that District 22 was a relatively new district of Tehran and people who lived in District 22 had similar social statuses. Moreover, it could be concluded that homogeneity was higher in District 22 than in other districts of Tehran. Therefore, effects of household food security on HRQOL were reported high in Districts 2, 7, 8, 12, 16, 20 and 21, respectively. Thus, it can be concluded that effects of household food security on HRQOL varied in various districts of Tehran. For example, effects of household food security on HRQOL was low in Districts 3, 5 and 13, respectively. Additionally, effects of household food security on HRQOL in District 1 and 16 was twice that in Districts 3, 5 and 13.

Studies in several countries have shown associations between the HFS and HRQOL. Gray et al. reported that HFS was positively correlated with HRQOL in Indians (29). A study in the United States demonstrated that individuals living in food secure households had a higher HRQOL than those living in food insecure households (30). In a study on people living with HIV in Uganda, significantly positive relationships were detected between high-quality food access and HRQOL (31). 
Table 3. Comparison of the participants' HRQOL mean scores based on the HFS statuses in 22 districts of Tehran

\begin{tabular}{|c|c|c|c|c|}
\hline Districts & $\begin{array}{l}\text { Household Food } \\
\text { Security }\end{array}$ & $\mathrm{SD} \pm$ Mean & $95 \%$ CI for Mean & P-value \\
\hline \multirow[t]{3}{*}{1} & Yes & $17.0 \pm 65.5$ & $(64.5,66.5)$ & $<0.001$ \\
\hline & No & $18.4 \pm 56.6$ & $(54.5,58.6)$ & \\
\hline & Yes & $19.1 \pm 64.9$ & $(63.8,66.0)$ & $<0.001$ \\
\hline \multirow[t]{2}{*}{2} & No & $20.5 \pm 54.3$ & $(52.2,56.3)$ & \\
\hline & Yes & $18.4 \pm 66.6$ & $(65.5,67.7)$ & $<0.001$ \\
\hline \multirow[t]{2}{*}{3} & No & $18.7 \pm 59.0$ & $(56.6,61.3)$ & \\
\hline & Yes & $18.8 \pm 64.1$ & $(62.8,65.4)$ & $<0.001$ \\
\hline \multirow[t]{2}{*}{4} & No & $19.3 \pm 56.1$ & $(54.5,57.8)$ & \\
\hline & Yes & $19.0 \pm 63.8$ & $(62.6,65.0)$ & $<0.001$ \\
\hline \multirow[t]{2}{*}{5} & No & $19.4 \pm 56.6$ & $(54.7,58.4)$ & \\
\hline & Yes & $18.0 \pm 63.4$ & $(62.3,64.4)$ & $<0.001$ \\
\hline \multirow[t]{2}{*}{6} & No & $17.0 \pm 55.8$ & $(53.7,57.9)$ & \\
\hline & Yes & $19.3 \pm 66.7$ & $(65.4,68.0)$ & $<0.001$ \\
\hline \multirow[t]{2}{*}{7} & No & $20.6 \pm 56.3$ & $(54.7,58.0)$ & \\
\hline & Yes & $19.2 \pm 62.8$ & $(61.6,64.0)$ & $<0.001$ \\
\hline \multirow[t]{2}{*}{8} & No & $20.2 \pm 52.6$ & $(50.7,54.5)$ & \\
\hline & Yes & $19.4 \pm 62.8$ & $(61.3,64.2)$ & $<0.001$ \\
\hline \multirow[t]{2}{*}{9} & No & $19.6 \pm 54.1$ & $(52.6,55.6)$ & \\
\hline & Yes & $18.2 \pm 65.9$ & $(64.6,67.1)$ & $<0.001$ \\
\hline \multirow[t]{2}{*}{10} & No & $19.3 \pm 59.4$ & $(57.9,60.9)$ & \\
\hline & Yes & $19.6 \pm 63.5$ & $(62.2,64.8)$ & $<0.001$ \\
\hline \multirow[t]{2}{*}{11} & No & $19.4 \pm 54.1$ & $(52.4,55.9)$ & \\
\hline & Yes & $17.6 \pm 60.3$ & $(59.1,61.6)$ & $<0.001$ \\
\hline \multirow[t]{2}{*}{12} & No & $18.7 \pm 52.1$ & $(50.5,53.6)$ & \\
\hline & Yes & $18.3 \pm 61.6$ & $(60.4,62.8)$ & $<0.001$ \\
\hline \multirow[t]{2}{*}{13} & No & $19.5 \pm 55.2$ & $(53.3,57.1)$ & \\
\hline & Yes & $19.0 \pm 61.2$ & $(59.9,62.6)$ & $<0.001$ \\
\hline \multirow[t]{2}{*}{14} & No & $19.6 \pm 52.1$ & $(50.4,53.7)$ & \\
\hline & Yes & $19.8 \pm 63.2$ & $(61.8,64.7)$ & $<0.001$ \\
\hline \multirow[t]{2}{*}{15} & No & $19.1 \pm 55.8$ & $(54.5,57.2)$ & \\
\hline & Yes & $18.7 \pm 61.8$ & $(60.5,63.1)$ & $<0.001$ \\
\hline \multirow[t]{2}{*}{16} & No & $18.0 \pm 52.6$ & $(51.1,54.1)$ & \\
\hline & Yes & $18.0 \pm 63.8$ & $(62.4,65.3)$ & $<0.001$ \\
\hline \multirow[t]{2}{*}{17} & No & $17.8 \pm 56.9$ & $(55.6,58.3)$ & \\
\hline & Yes & $18.0 \pm 62.9$ & $(61.6,64.2)$ & $<0.001$ \\
\hline \multirow[t]{2}{*}{18} & No & $18.7 \pm 55.3$ & $(54.1,56.6)$ & \\
\hline & Yes & $19.0 \pm 63.7$ & $(62.4,65.1)$ & $<0.001$ \\
\hline \multirow[t]{2}{*}{19} & No & $18.9 \pm 55.1$ & $(53.6,56.5)$ & \\
\hline & Yes & $19.5 \pm 65.0$ & $(63.8,66.2)$ & $<0.001$ \\
\hline \multirow[t]{2}{*}{20} & No & $20.6 \pm 54.9$ & $(53.2,56.6)$ & \\
\hline & Yes & $19.1 \pm 63.1$ & $(61.9,64.4)$ & $<0.001$ \\
\hline \multirow[t]{2}{*}{21} & No & $19.2 \pm 53.2$ & $(51.7,54.8)$ & \\
\hline & Yes & $18.3 \pm 64.6$ & $(63.2,66.0)$ & $<0.001$ \\
\hline 22 & No & $19.4 \pm 58.3$ & $(56.2,60.4)$ & \\
\hline
\end{tabular}


Mahboobeh Darman, et al: The association of HFS and HRQOL in different districts of Tehran

Table 4. Adjusted analysis ${ }^{1}$ of HFS on HRQOL in 22 districts of Tehran based on the multiple linear regression model

\begin{tabular}{|c|c|c|c|c|c|}
\hline \multirow[t]{2}{*}{ Districts } & \multicolumn{2}{|c|}{ Non-standardized Coefficients } & \multirow{2}{*}{$\begin{array}{c}\text { Standardized Coefficients } \\
\text { Beta }\end{array}$} & \multirow[b]{2}{*}{$\mathrm{t}$} & \multirow{2}{*}{$P$-value } \\
\hline & $\beta$ & SE & & & \\
\hline 1 & 8.16 & 1.26 & 0.195 & 6.49 & $<0.001$ \\
\hline 2 & 7.71 & 1.22 & 0.166 & 6.31 & $<0.001$ \\
\hline 3 & 4.92 & 1.39 & 0.102 & 3.53 & $<0.001$ \\
\hline 4 & 6.08 & 1.12 & 0.151 & 5.41 & $<0.001$ \\
\hline 5 & 4.95 & 1.20 & 0.116 & 4.12 & $<0.001$ \\
\hline 6 & 5.80 & 1.19 & 0.126 & 4.87 & $<0.001$ \\
\hline 7 & 7.10 & 1.06 & 0.171 & 6.66 & $<0.001$ \\
\hline 8 & 7.83 & 1.12 & 0.181 & 6.97 & $<0.001$ \\
\hline 9 & 6.33 & 1.05 & 0.159 & 6.04 & $<0.001$ \\
\hline 10 & 5.09 & 0.96 & 0.132 & 5.30 & $<0.001$ \\
\hline 11 & 6.70 & 1.11 & 0.159 & 6.02 & $<0.001$ \\
\hline 12 & 7.32 & 1.01 & 0.195 & 7.21 & $<0.001$ \\
\hline 13 & 4.12 & 1.15 & 0.102 & 3.60 & $<0.001$ \\
\hline 14 & 6.95 & 1.09 & 0.173 & 6.38 & $<0.001$ \\
\hline 15 & 5.92 & 1.01 & 0.149 & 5.87 & $<0.001$ \\
\hline 16 & 8.12 & 1.02 & 0.214 & 8.05 & $<0.001$ \\
\hline 17 & 5.77 & 1.09 & 0.158 & 5.31 & $<0.001$ \\
\hline 18 & 6.85 & 0.97 & 0.179 & 7.09 & $<0.001$ \\
\hline 19 & 6.88 & 1.03 & 0.176 & 6.69 & $<0.001$ \\
\hline 20 & 7.51 & 1.03 & 0.177 & 7.25 & $<0.001$ \\
\hline 21 & 7.58 & 1.03 & 0.189 & 7.35 & $<0.001$ \\
\hline 22 & 2.89 & 1.27 & 0.072 & 2.28 & 0.023 \\
\hline
\end{tabular}

${ }^{1}$ Adjusted by age, gender, level of education, marital status, family size, BMI, wealth index and deprivation index

Relationships between HRQOL and household food insecurity (HFI) in Texas have been reported by Sharkey et al.; where, $27.8 \%$ of the surveyed people lived in households with food insecurity. Food insecurity in rural households was one of the major factors affecting QOL; however, the relationship was not seen in urban households (32). Similarly, Alfred et al. investigated relationships between the HFI and health statuses of people in a region of the United States (Appalachia) and found that 23\% of the surveyed households included food insecure statuses. They reported that people of food insecure families included a lower QOL in all aspects, compared to that people of food secure households did (33). In a study on assessing food insecurity, mental health and QOL of the people living with HIV and receiving antiviral therapy, prevalence of HFI was $38.7 \%$. Decreased mental health and food insecurity led to decreases in QOL of HIV-infected patients receiving antiviral therapy. The MLR model demonstrated significantly positive relationships between HFS and HRQOL with adjusting variables of age, gender, education, marital status, family size, BMI, wealth index and deprivation index as a higher food security led to a better HRQOL (34). Accordingly, HFI usually occured due to decreases in variety of foods consumed in households. One of the major consequences of HFI included changes in food receiving ways and food diversity in households (35). Assessment of the pattern of food consumption in households showed that food insecure households were majorly focused on receiving energy or filling their stomachs. Therefore, such families consumed cheap foods with high energies but low micronutrients, foods poor in fruits, vegetables, milks and dairies as well as low-health diets (36-38). As a first consequence of insufficient access to food resources, variety of foods in such families decreased (39).

The current results showed that ages over 42 years (middle-aged and elderly groups), gender, educational level, family size, BMI, wealth index and deprivation index were significantly linked to HRQOL. Based on the results of principal component analysis, wealth index and deprivation index included significant effects on QOL. People in the fourth (richer) and fifth (richest) quintiles included higher QOL scores, compared to that people in the lower quintile did. A study on low-income families in Hong Kong showed that the QOL of people with incomes below $50 \%$ of the average population and somehow on the verge of poverty scored lower in physical and mental health statutes (40). In the United Kingdom, Netuveli at al. (2002) reported that efforts to improve QOL in early old ages needed solving of financial problems, functional limitations and ability to leave inappropriate neighborhoods. If these factors were controlled, there were possibilities of improving QOL in early old ages (41). Tajvari et al. reported that elderly people in Tehran suffered from a relatively poor HRQL, especially elder women and those with low educational levels. To improve the QOL of older Iranians, further attentions should be specified to various aspects of their lives, including health and economic situations (42). In a study on the relationships of food insecurity and poor diet quality with 
decreased QOL in the elderly people by Russell et al., significant relationships were reported between decreased physical and mental health statutes with food insecurity and shortage of diets (43). As a result, households with a better socioeconomic situation included a higher QOL. Gender and literacy were two sociocultural variables, which could affect the HFS statuses. Aging changed personal position of the family members as reproductive indivisuals and thus increased their shares of quality foods. Overweight and obesity as indicators of HFS could affect the QOL statutes. Bottone et al. indicated that negative effects of various BMI categories on QOL included obese and morbidly obese categories, especially for those of underweight, significantly much more important than other chronic conditions (44).

\section{Strengths and Limitations}

Uses of large sample size and MLR model were the major strengths of the present study. This study was a cross-sectional study; thus, it did not establish causal relationships between HFS and HRQOL. However, this study provided valuable information on food security statuses of the households in various districts of Tehran.

\section{Conclusion}

Based on the results, it can be concluded that HFS is an important factor in improvement of HRQOL. Prevalence of food insecurity in the community is an alarm for the administrators. Moreover, existence of food insecurity includes numerous consequences and effects. Since HFI is an alarm for decreased QOL in Tehran as the largest and most populated city of Iran, the present study provides valuable information on food security status and HRQOL of the households in 22 districts of the city. Thus, it is recommended that policy makers prepare efficient intervention programs to promote QOL of urban households based on the social determinants in each district.

\section{Acknowledgement}

The authors appreciate participants of this study.

\section{Financial disclosure}

The authors declared no financial interest.

\section{Funding/Support}

No Financial Support

\section{References}

1. Ferrans CE. Quality of life: Conceptual issues. Seminars in Oncology Nursing [Internet]. Elsevier BV; 1990 Nov;6(4):248-54. Available from: http://dx.doi.org/10.1016/0749-2081(90)90026-2
2. Leininger M. HRQOL from a transcultural nursing perspective. Nurse Sci Q 1994; 7(1): 22-28.

3. Barofsky, Ivan. Quality of Life Research 13, no. 5 (2004): 1021-024. Accessed January 16, 2021. http://www.jstor.org/stable/4038910.

4. Furness BW, Simon PA, Wold CM, Asarian-Anderson J. Prevalence and predictors of food insecurity among lowincome households in Los Angeles County. Public Health Nutrition [Internet]. Cambridge University Press (CUP); 2004 Sep;7(6):791-4. Available from: http://dx.doi.org/10.1079/phn2004608

5. Melgar-Quinonez HR, Zubieta AC, MkNelly B Nteziyaremye A, Gerardo MFD, Dunford C. Household Food Insecurity and Food Expenditure in Bolivia, Burkina Faso and the Philippines. The Journal of Nutrition [Internet]. Oxford University Press (OUP); 2006 May 1;136(5):1431S-1437S. Available from: http://dx.doi.org/10.1093/jn/136.5.1431s

6. Bickel G, Nord M, Price C, Hamilton W, Cook J. Guide to Measuring Household Food Security.3nd ed. U.S. Department of Agriculture Food and Nutr Service; 2000

7. Ministry of Health and Medical Education, Office of Nutrition Improvement. National Monitoring Site for Food and Nutrition Security in Iran and compilation the first map of the state of food security in the country (SAMPAT Research); 2011 Winter.

8. The State of Food Security and Nutrition in the World 2018. The State of Food Security and Nutrition in the World [Internet]. UN; 2019 Feb 19; Available from: http://dx.doi.org/10.18356/c94f150c-en

9. Hakim S, Dorosty A.R, Eshraqian M.R. Relationship between Food Insecurity and Some of Socioeconomic Factors with BMI among Women in Dezfoul. Iranian $\mathbf{J}$ of Shool of Public Health 2011; 2: 55-66 [In Persian]

10. Abolhassani F, Mohajeri Tehrani MR, Tabatabaei O, Larijani B. Burden of diabetes and its complications in Iran in year 2000. Iranian J of Diabetes and Lipid Disorders 2005; 5: 3548.

11. Gholami A, Moosavi Jahromi L, Zarei E, Dehghan A. Application of whoHRQOL-bref in measuring HRQOL in health-care staff. Int J Prev Med 2013; 4: 809-17.

12. Abdollahpour I, Salimi Y, Nedjat SN, Jorjoran shushtari Z. HRQOL and effective factors on it among governmental staff in boukan city. Urmia J Med sci 2011;22: 40-7. Persian

13. Gholami A, Azini M, Borji A, Shirazi F, Sharafi Z, Zarei E. HRQOL in Patients with Type 2 Diabetes: Application of WHOHRQOL-BREF Scale. Shiraz E-Med J 2013; 14(3):16271.

14. Nedjat S, Montazeri A, Holakouie K, Mohammad K, Majdzadeh R. HRQOL of Tehran's Population by WHOHRQOL-BREF questionnaire in 2005; Hakim Research J 2007; 10(3): 1- 8

15. Rashedi V, Asadi-Lari M, Delbari A, Fadayevatan R, Borhaninejad V, Foroughan M. Prevalence of diabetes type 2 in older adults: Findings from a large population-based survey in Tehran, Iran (Urban HEART-2). Diabetes \& Metabolic Syndrome: Clinical Research \& Reviews [Internet]. Elsevier BV; 2017 Nov;11:S347-S350. Available from: http://dx.doi.org/10.1016/j.dsx.2017.03.014

16. Kiadaliri AA, Asadi-Lari M, Kalantari N, Jafari M, Vaez Mahdavi MR, Faghihzadeh S. Absolute and relative educational inequalities in obesity among adults in Tehran: 
Findings from the Urban HEART study-2. Obesity Research \& Clinical Practice [Internet]. Elsevier BV; 2016 Sep;10:S57S63. Available from: http://dx.doi.org/10.1016/j.orcp.2015.05.002

17. Asadi-Lari M, Salimi Y, Vaez-Mahdavi MR, Faghihzadeh S, Haeri Mehrizi AA, Jorjoran Shushtari Z, et al. SocioEconomic Status and Prevalence of Self-Reported Osteoporosis in Tehran: Results from a Large PopulationBased Cross-Sectional Study (Urban HEART-2). Journal of Urban Health [Internet]. Springer Science and Business Media LLC; 2018 Apr 10;95(5):682-90. Available from: http://dx.doi.org/10.1007/s11524-018-0246-6

18. Dastgiri S, Tutunchi H, Ostadrahimi A, Mahboob S. Sensitivity and specificity of a short questionnaire for food insecurity surveillance in Iran. Food Nutr Bull.2007; 28(1): 55-58.

19. Gholami A, Foroozanfar Z.Household food security status in the Northeast of Iran: a cross-sectional study. Med J of the Islamic Republic of Iran 2015 July

20. Ware JE, Kosinski M, Keller SD. A 12-Item Short-Form Health Survey. Medical Care [Internet]. Ovid Technologies (Wolters Kluwer Health); 1996 Mar; 34(3):220 33.[PubMed][Cross Ref]. Available from: http://dx.doi.org/10.1097/00005650-199603000-00003

21. Montazeri A, Vahdaninia M, Mousavi SJ, Omidvari S. The Iranian version of 12-item Short Form Health Survey (SF-12): factor structure, internal consistency and construct validity. BMC Public Health [Internet]. Springer Science and Business Media LLC; 2009 Sep 16;9(1). Available from: http://dx.doi.org/10.1186/1471-2458-9-341

22. Lim L, Seubsman S, Sleigh A. Thai SF-36 health survey: tests of data quality, scaling assumptions, reliability and validity in healthy men and women. Health and Quality of Life Outcomes [Internet]. Springer Science and Business Media LLC; 2008;6(1):52. [PMC free article] [PubMed] [Cross Ref] Available from: http://dx.doi.org/10.1186/1477-7525-6-52

23. Ware JE, Kosinski M.M, Keller, SD. How to Score the SF-12 Physical and Mental Health Summary Scales. 3. Lincoln, RI: Quality Metric Inc; 1998.

24. Ware JE, Gandek B. Overview of the SF-36 Health Survey and the International Quality of Life Assessment (IQOLA) Project. Journal of Clinical Epidemiology [Internet]. Elsevier BV; 1998 Nov;51(11):903-12. Available from: http://dx.doi.org/10.1016/s0895-4356(98)00081-X

25. DHS Program (Demographic and Health Survey). Available at: http://www.dhsprogram.com/topics/wealth- index/Index. cfm.

26. Yousefi M, Assari Arani A, Sahabi B, Kazemnejad A, Fazaeli $\mathrm{S}$. The financial contribution of households using by health services. Journal of payavard salamat. 2015 Mar 10; 8(6):51727.

27. Noble M, Wright G, Dibben C, Smith GA, McLennan D, Anttila C, Barnes H, Mokhtar C, Noble S, Avenell D, Gardner J. The English indices of deprivation 2004 (revised). Report to the Office of the Deputy Prime Minister. London: Neighbourhood Renewal Unit. 2004.

28. Townsend P. Deprivation. Journal of Social Policy. Cambridge University Press; 1987; 16(2):125-46.

29. Gray J.S, Gonzaga K, Penland J.G, Lukaski H.C, Stensland P. Food Security, Depression and Quality of Life in Northern Plains Indians. J of Indigenous Research 2014; 4(2015): 1-6.
30. Palermo T, Rawat R, Weiser SD, Kadiyala S. Food access and diet quality are associated with quality of life outcomes among HIV-infected individuals in Uganda. PloS one. 2013 Apr 18;8(4):e62353.

31. Palermo T, Rawat R, Weiser SD, Kadiyala S. Food Access and Diet Quality Are Associated with Quality of Life Outcomes among HIV-Infected Individuals in Uganda. Beck EJ, editor. PLoS ONE [Internet]. Public Library of Science

32. Sharkey JR, Johnson CM, Dean WR. Relationship of Household Food Insecurity to Health-Related Quality of Life HRQOL in a Large Sample of Rural and Urban Women. Women Health 2011; 51(5): 442-60

33. Pkley AM, Holben DM, Graham AS, Simpson C. Food Security and Perceptions of Health Status: A Preliminary Study in Rural Appalachia. J of Rural Health 2002; 18( 3): 447-54

34. Tesfaye M, Kaestel P, Olsen MF, Girma T, Yilma D, Abdissa A, Ritz C, Prince M, Friis H, Hanlon C. Food insecurity, mental health and quality of life among people living with HIV commencing antiretroviral treatment in Ethiopia: a crosssectional study. Health and quality of life outcomes. 2016 Dec;14(1):1-8

35. Alimoradi Z, Kazemi F, Estaki T, Mirmiran P. Household food security in Iran: systematic review of Iranian articles. Adv Nurs Midwifery. 2015 Jun 10;24(4):63-76.

36. Dixon LB, Winkleby MA, Radimer KL. Dietary Intakes and Serum Nutrients Differ between Adults from FoodInsufficient and Food-Sufficient Families: Third National Health and Nutrition Examination Survey, 1988-1994. The Journal of Nutrition [Internet]. Oxford University Press (OUP); 2001 Apr 1;131(4):1232-46. Available from: http://dx.doi.org/10.1093/jn/131.4.1232.

37. Drewnowski A, Specter S. Poverty and obesity: the role of energy density and energy costs. The American Journal of Clinical Nutrition [Internet]. Oxford University Press (OUP); 2004 Jan 1;79(1):6-16. Available from: http://dx.doi.org/10.1093/ajen/79.1.6

38. KENDALL A, OLSON CM, FRONGILLO EA. Relationship of Hunger and Food Insecurity to Food Availability and Consumption. Journal of the American Dietetic Association [Internet]. Elsevier BV; 1996 Oct; 96(10):1019-24. Available from: http://dx.doi.org/10.1016/s0002-8223(96)00271-4

39. Hasan-Ghomi M, Mirmiran P, Amiri Z, Asghari G, Sadeghian S, Sarbazi N, Azizi F. The association of food security and dietary variety in subjects aged over 40 in district 13 of Tehran. Iranian Journal of Endocrinology and Metabolism. 2012; 14(4).

40. Lo Kuen Lam C, Yawei Guo V, King HoWong K, Yee Tak Yu E, Siu Cheung Fung C. Poverty and health-related quality of life of people living in Hong Kong: comparison of individuals from low-income families and the general population. Journal of Public Health. 2016 may; 39(2): 258265.

41. Netuveli G. Quality of life at older ages: evidence from the English longitudinal study of aging (wave 1). Journal of Epidemiology \& Community Health [Internet]. BMJ; 2006 Apr 1;60(4):357-63. Available from: http://dx.doi.org/10.1136/jech.2005.040071

42. Tajvar M, Arab M, Montazeri A. Determinants of healthrelated quality of life in elderly in Tehran, Iran. BMC Public Health [Internet]. Springer Science and Business Media LLC; 
2008 Sep $22 ; 8(1) . \quad$ Available from: http://dx.doi.org/10.1186/1471-2458-8-323.

43. Russell J, Flood M, Yeatman H, Wang J, Mitchell P. Food insecurity and poor diet quality are associated with reduced quality of life in older adults. Nutrition \& Dietetics 2016; 73: 50-58.
44. Bottone FG, Hawkins K, Musich S, Cheng Y, Ozminkowski RJ, Migliori RJ, et al. The relationship between body mass index and quality of life in community-living older adults living in the United States. The journal of nutrition, health \& aging [Internet]. Springer Science and Business Media LLC; 2013 Mar 18; 17(6):495-501. Available from: http://dx.doi.org/10.1007/s12603-013-0022-y. 